\title{
Plasma Spectral Measurements in the D-Module of the GAMMA 10/PDX End-Cell $\left.{ }^{*}\right)$
}

\author{
Yasunari HOSODA, Yousuke NAKASHIMA, Yohei IIDA, Katsuhiro HOSOI, Kazuya ICHIMURA, \\ Hisato TAKEDA, Satoru KIGURE, Shigehito TAKAHASHI, Miki IWAMOTO, Keita SHIMIZU, \\ Yoshiki SHOU, Takanobu NAGAYA, Masashi YOSIKAWA, Kensuke OKI, Mizuki SAKAMOTO, \\ Yu NAGATUKA, Motoki YOSHIKAWA, Ryo NOHARA and Makoto ICHIMURA \\ Plasma Research Center, University of Tsukuba, Tsukuba, Ibaraki 305-8577, Japan
}

(Received 11 December 2013 / Accepted 20 March 2014)

\begin{abstract}
In this paper, results of spectral measurement in the end-cell of the GAMMA 10/PDX are described. A spectral measurement system consisting of two spectrometers was developed in order to measure the detailed radiation behavior in D-module. Firstly, angular dependence of the V-shaped target plate on the spatial distribution of the $\mathrm{H} \alpha$ radiance was investigated. It is found that the spectral distribution in $\mathrm{H} \alpha$ intensity along the axial direction is affected by the angle of the target plate. Next, in the experiment with $\mathrm{H}_{2}$ and Ar gas injection, primary 17 line spectra of Ar I were identified and the radiation loss from Ar neutrals was also evaluated from intensity of spectra. A correlation between the power of radiation loss and the electron temperature in D-module are recognized. The correlation between radiation power and electron temperature is also discussed from the view point of radiation cooling.
\end{abstract}

(C) 2014 The Japan Society of Plasma Science and Nuclear Fusion Research

Keywords: GAMMA 10/PDX, D-module, spectral measurements, divertor, radiation cooling

DOI: $10.1585 /$ pfr.9.3402087

\section{Introduction}

Protection of plasma-facing components from the high-temperature plasma is one of the most important issues in order to control fusion plasma. Therefore, it is very effective to apply magnetic divertor which reduces the interaction of high heat-flux plasma to the plasma facing components. The reduction of the heat road to the divertor plates by promoting the radiation cooling is an urgent research subject to form the detached plasma.

In the GAMMA 10/PDX tandem mirror, high temperature plasmas are produced in the central-cell. Since the charged particles are transported to the GAMMA 10/PDX end-cell in a high temperature state, we can conduct the experiment under the condition resembling the high performance plasma device. Furthermore, the open magnetic field configuration in the end-cell is suitable for the divertor simulation experiment. In GAMMA 10/PDX, we have conducted the divertor simulation research using end-loss plasma flow with high heat-flux from the end-cell [1-5]. Last year, the divertor simulation experimental module (Dmodule) was installed in the west end-cell.

One of the main objectives in the divertor simulation experiments is to produce detached plasma in D-module.

In this study, the plasma cooling mechanism toward the detached plasma is investigated by injecting some kind

author'se-mail: hosoda_yasunari@prc.tsukuba.ac.jp

*) This article is based on the presentation at the 23rd International Toki Conference (ITC23). of gases (Ar, $\mathrm{Ne}, \mathrm{N}_{2}$, etc...). In order to evaluate the radiation cooling due to impurity particles, a high-sensitive, high-resolution spectroscopic system has

developed, and the gas injection experiment was performed with $\mathrm{H}_{2}$ and $\mathrm{Ar}$ gases. In this experiment, we measured the radiance of $\mathrm{H} \alpha$ emission $(656.27 \mathrm{~nm})$ while changing the angle of target plate and the viewing position of spectrometer in order to obtain basic data of radiation behavior in D-module without gas injection.

In section 2, the details of GAMMA 10/PDX and Dmodule are described. In section 3 , the diagnostic system used in the experiment is described and experimental results are shown in section 4 . The summary and future plan are presented in section 5 .

\section{GAMMA 10/PDX}

GAMMA 10/PDX is a tandem mirror device in which high temperature hydrogen plasmas are produced with Ion Cyclotron Range of Frequency (ICRF) heating (Fig. 1). The total length of GAMMA 10/PDX is $27 \mathrm{~m}$, and the volume of the vacuum vessel is $150 \mathrm{~m}^{3}$. GAMMA 10/PDX consists of central-cell, anchor-cell, plug/barrier-cell and end-cell. The main confinement region of GAMMA 10/PDX is the central cell $(Z=-300 \sim+300 \mathrm{~cm})$. The initial plasma produced by the plasma gun is heated by ICRF waves and confined by magnetic mirror field and electrostatic potential. Two choke coils and ten pancake coils are installed and form the simple axi-symmetric magnetic mir- 
ror configuration in the central-cell. In the case of standard magnetic field configuration of GAMMA 10/PDX, the magnetic field intensity in the central-cell is $0.41 \mathrm{~T}$ and the mirror ratio is 5 . The both ends of the central-cell are connected to east/west anchor-cells, which keep the plasma stably. Three baseball coils are installed and form the average-minimum-B configuration in each anchor-cell. In the middle of the anchor-cell $(Z= \pm 520 \mathrm{~cm})$, the magnetic field intensity is $0.61 \mathrm{~T}$ and the mirror ratio is 3 . The outside of anchor-cells are east/west plug/barrier-cells, in which plug potential and barrier potential are produced. In the plug/barrier-cell, the axially symmetric mirror magnetic field configuration is formed.

The intensity of magnetic field in the mid plane of the plug/barrier-cell and that in the mirror throat of both ends are $0.5 \mathrm{~T}$ and $3 \mathrm{~T}$, respectively. East/west end-cells are located to the outside of plug/barrier-cells in which the plasma flow out.

In D-module, two target plates made of tungsten are mounted in $\mathrm{V}$ shape, as shown in Fig. 2. On the upper target plate, 13 electrostatic probes are installed and spatial distribution of the electron temperature and the density are measured on the target plate surface. On the lower target

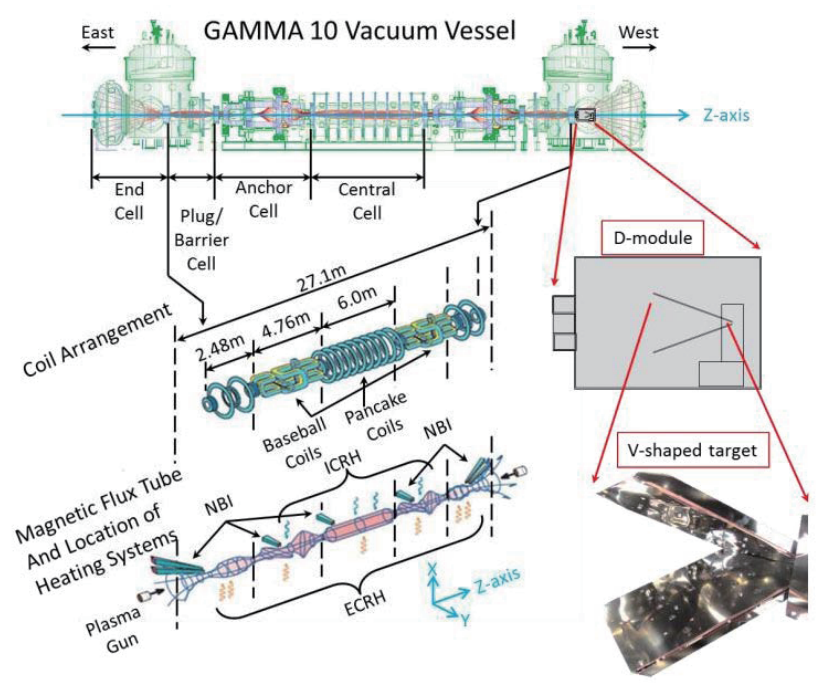

Fig. 1 Schematic view of GAMMA 10/PDX and D-module.

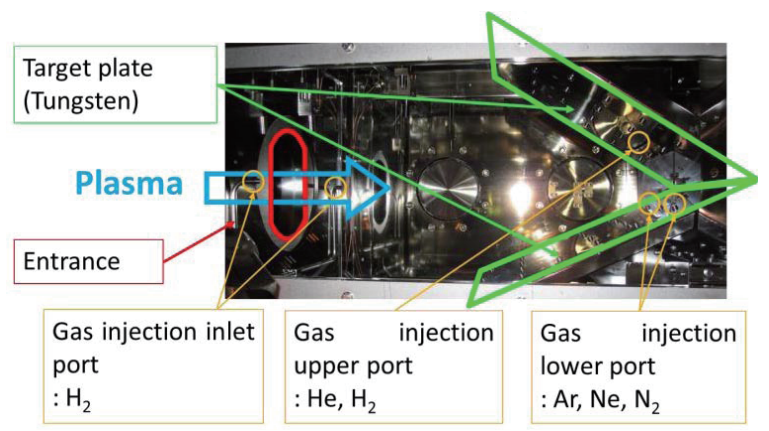

Fig. 2 Interior view of D-module. plate, 13 calorimeters are installed and the heat flux onto the target plate surface is measured. The angle of the Vshaped target can be changed between 15 and 80 degrees.

In this study, we set the angle of the V-shaped target at 3 angles (30, 45, 60 degrees). Gas injection system for radiation cooling was also installed on the plate. From this year, new gas injection system was installed near the entrance of D-module.

\section{Diagnostic System}

Figure 3 shows the schematic diagram of spectroscopic system installed in the west end-cell. The system consists of a compact-type spectrometer (USB2000+) with large band-pass $(698 \mathrm{~nm})$ and a high sensitivity spectrometer (SR500i) with high wavelength resolution $(0.031 \mathrm{~nm}$ FWHM@656.27 nm). USB2000+ is used for measuring the spectra in wide wavelength range with the exposure time of $5 \mathrm{~ms}$ in this study, as shown in Table 1. SR500i is used for identifying the spectra from various line emissions in high wavelength resolution. The wavelength resolution and band-pass is adjustable by changing the diffraction grating, as shown in Table 2. In this study, we choose the following parameters (Grating: $1799 \mathrm{~L} / \mathrm{mm}$, Slit width: $10 \mu \mathrm{m}$, Exposure time: $35 \mathrm{~ms}$ ).

The sensitivity calibration of those spectrometers was performed by measuring the emission spectrum of standard light. The emission of standard light is reflected using the certified reflectance standard.

In the gas injection experiments with Ar, we identified wavelength containing neutral Ar emission and calculated

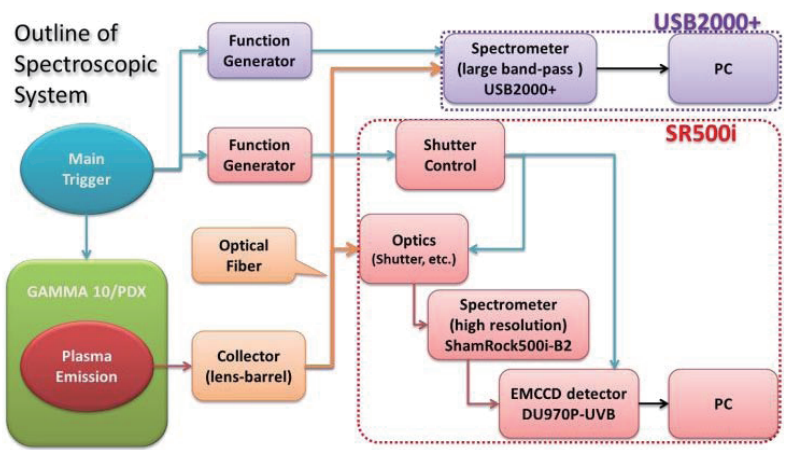

Fig. 3 Schematic diagram of spectroscopic system.

Table 1 Construction of spectroscopic system.

\begin{tabular}{|l|l|}
\hline Specifications Summary & USB2000+ \\
\hline Gratings & Holographic \\
\hline Wavelength resolution & $2.94 \mathrm{~nm} @$ H $\alpha$ FWHM \\
\hline Band-pass & $698 \mathrm{~nm}(190-888 \mathrm{~nm})$ \\
\hline Slit width & $25 \mu \mathrm{m}$ \\
\hline Pixel size & $14 \mu \mathrm{m} \times 200 \mu \mathrm{m}(2048$ pixels $)$ \\
\hline Exposure time & $5 \mathrm{~ms}-$ \\
\hline
\end{tabular}


Table 2 Construction of spectroscopic system.

\begin{tabular}{|l|l|}
\hline Specifications Summary & SR500i-B2, DU970P-UVB \\
\hline Gratings & $150 / 1200 / 1799 \mathrm{~L} / \mathrm{mm}$ \\
\hline Wavelength resolution & $0.031 \mathrm{~nm} @ 811.53 \mathrm{~nm}$ FWHM $(1799 \mathrm{~L} / \mathrm{mm})$ \\
\hline Band-pass & $26 \mathrm{~nm}(1799 \mathrm{~L} / \mathrm{mm})$ \\
\hline Slit widths range & Manual or motorized $10 \mu \mathrm{m}$ to $2.5 \mathrm{~mm}$ \\
\hline Pixel size & $16 \mu \mathrm{m} \times 16 \mu \mathrm{m}(1600 \times 200$ pixels $)$ \\
\hline Exposure time & $10 \mathrm{~ms}-$ \\
\hline
\end{tabular}

power of radiation loss on emission spectra measured in this experiment by using SR500i.

\section{Experimental Results and Discus- sion}

\subsection{Angle dependence of $\mathrm{V}$-shaped target}

In order to obtain basic data of radiation behavior in D-module without gas injection, the dependence for the angle of the $\mathrm{V}$-shaped target is investigated by using USB2000+.

Figure 4 shows the radiance of $\mathrm{H} \alpha$ in each angle and position. It is found that the radiance of $\mathrm{H} \alpha$ decreases from the entrance (Pos.2) to the V-shaped target (Pos.0). The electron density in D-module decreases according to the expansion of the magnetic field lines along the Z-axis. Since radiance is proportional to electron density, the decrease of the electron density seems to be one of the causes for the decrease of radiance.

As the angle of V-shaped target became small, the radiance of $\mathrm{H} \alpha$ increased at all positions. When the angle of the V-shaped target becomes small, the distance with the target plate becomes near, and hence, the effect of recycling seems to be dominant.

\subsection{Effect of Ar gas injection}

In order to evaluate the radiation loss power, gas injection experiments with $\mathrm{H}_{2}$ and $\mathrm{Ar}$ gas was carried out and Ar's line spectra were investigated between $680 \mathrm{~nm}$ and $860 \mathrm{~nm}$. Figure 5 shows an example of measured spectra in the case of Ar gas injection. In the case with $\mathrm{H}_{2}$ gas injection, the radiance of $\mathrm{H} \alpha$ and $\mathrm{H} \beta$ increased by 8 times. In the case of Ar gas injection, the line-spectra of Ar I were observed between 680 and $860 \mathrm{~nm}$. Firstly, primary seventeen line-spectra of Ar I were identified by using SR500i as shown in Fig. 6 [6]. Table 3 shows the configurations and the energy levels before and after the emission of those 17 spectra. Next, each power of the radiation loss was calculated by integrating those line spectra. In this study, the spectra which are smaller than these 17 spectra are processed as errors because they are small sufficiently. For integrating line spectra, the fitting with Gaussian function was used.

We evaluated the power of radiation loss on each ex-

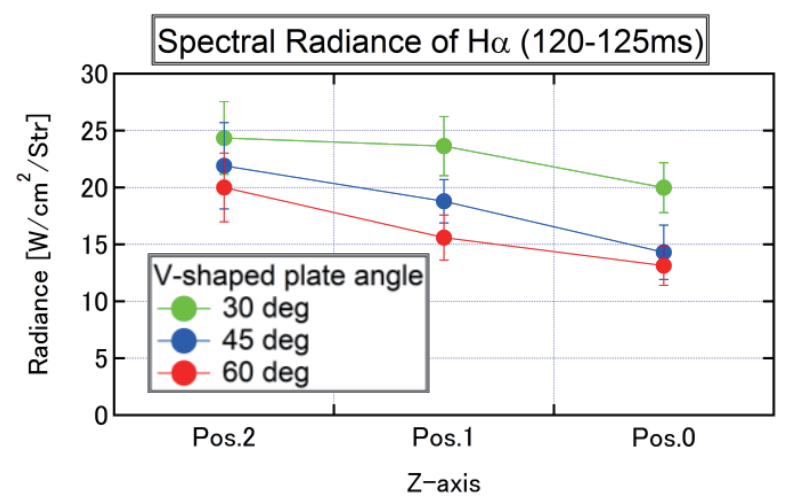

Fig. 4 Radiance of $\mathrm{H} \alpha$ in each angle and position.

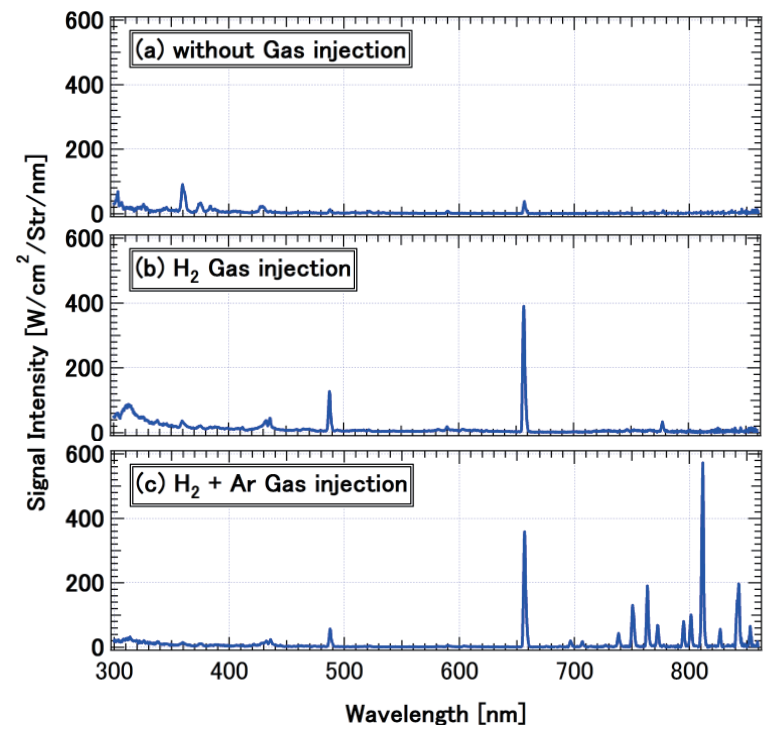

Fig. 5 Measured spectra in Ar gas injection experiment. (a) Without gas injection, (b) With $\mathrm{H}_{2}$ gas injection, (c) With $\mathrm{H}_{2}$ and $\mathrm{Ar}$ gas injection.

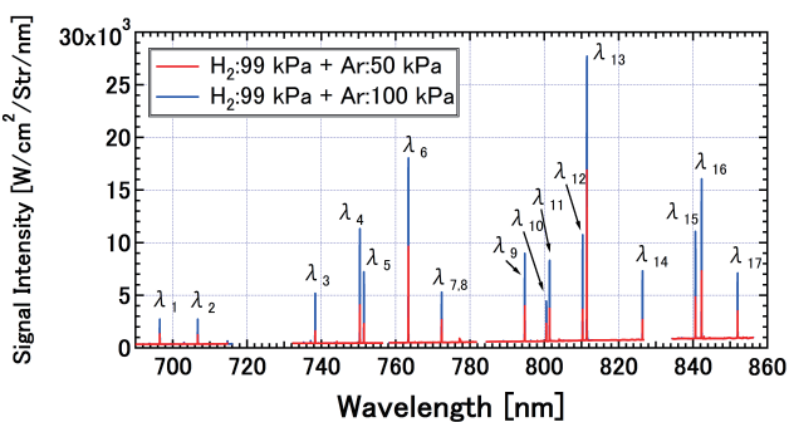

Fig. 6 Identification result of Ar I lines.

posure time by calculating total radiance of primary emission spectra of Ar I. Figure 7 shows the time behavior of radiance of neutral Ar emission. In Table 4, the radiance in the period $(t=160 \sim 170 \mathrm{~ms})$ and the electron temperature measured by the electrostatic probe are listed. It was confirmed that the electron temperature is decreased 
Table 3 Results of wavelength identification.

\begin{tabular}{|c|r|c|c|c|c|c|}
\hline \multicolumn{2}{|c|}{ Wavelength } & Aki & Lower Level & Ei & Upper Level & Ek \\
\hline & \multicolumn{1}{|c|}{$(\mathbf{n m})$} & \multicolumn{1}{c|}{$(\mathbf{s}-\mathbf{1})$} & Configlation & \multicolumn{1}{c|}{$(\mathbf{e V})$} & Configlation & (eV) \\
\hline$\lambda_{1}$ & 696.5431 & $6.39 \mathrm{E}+06$ & $4 \mathrm{~s}^{2}[3 / 2]_{2}{ }^{\circ}$ & 11.55 & $4 \mathrm{p}^{2}[1 / 2]_{1}$ & 13.33 \\
\hline$\lambda_{2}$ & 706.7218 & $3.80 \mathrm{E}+06$ & $4 \mathrm{~s}^{2}[3 / 2]_{2}{ }^{\circ}$ & 11.55 & $4 \mathrm{p}^{2}[3 / 2]_{2}$ & 13.30 \\
\hline$\lambda_{3}$ & 738.398 & $8.47 \mathrm{E}+06$ & $4 \mathrm{~s}^{2}[3 / 2]_{1}{ }^{\circ}$ & 11.62 & $4 \mathrm{p}^{2}[3 / 2]_{2}$ & 13.30 \\
\hline$\lambda_{4}$ & 750.3869 & $4.45 \mathrm{E}+07$ & $4 \mathrm{~s}^{2}[1 / 2]_{1}{ }^{\circ}$ & 11.83 & $4 \mathrm{p}^{2}[1 / 2]_{0}$ & 13.48 \\
\hline$\lambda_{5}$ & 751.4652 & $4.02 \mathrm{E}+07$ & $4 \mathrm{~s}^{2}[3 / 2]_{1}{ }^{\circ}$ & 11.62 & $4 \mathrm{p}^{2}[1 / 2]_{1}$ & 13.27 \\
\hline$\lambda_{6}$ & 763.5106 & $2.45 \mathrm{E}+07$ & $4 \mathrm{~s}^{2}[3 / 2]_{2}{ }^{\circ}$ & 11.55 & $4 \mathrm{p}^{2}[3 / 2]_{2}$ & 13.17 \\
\hline$\lambda_{7}$ & 772.3761 & $5.18 \mathrm{E}+06$ & $4 \mathrm{~s}^{2}[3 / 2]_{2}{ }^{\circ}$ & 11.55 & $4 \mathrm{p}^{2}[3 / 2]_{1}$ & 13.15 \\
\hline$\lambda_{8}$ & 772.4207 & $1.17 \mathrm{E}+07$ & $4 \mathrm{~s}^{2}[1 / 2]_{0}{ }^{\circ}$ & 11.72 & $4 \mathrm{p}^{2}[1 / 2]_{1}$ & 13.33 \\
\hline$\lambda_{9}$ & 794.8176 & $1.86 \mathrm{E}+07$ & $4 \mathrm{~s}^{2}[1 / 2]_{0}{ }^{\circ}$ & 11.72 & $4 \mathrm{p}^{2}[3 / 2]_{1}$ & 13.28 \\
\hline$\lambda_{10}$ & 800.6157 & $4.90 \mathrm{E}+06$ & $4 \mathrm{~s}^{2}[3 / 2]_{1}{ }^{\circ}$ & 11.62 & $4 \mathrm{p}^{2}[3 / 2]_{2}$ & 13.17 \\
\hline$\lambda_{11}$ & 801.4786 & $9.28 \mathrm{E}+06$ & $4 \mathrm{~s}^{2}[3 / 2]_{2}{ }^{\circ}$ & 11.55 & $4 \mathrm{p}^{2}[5 / 2]_{2}$ & 13.09 \\
\hline$\lambda_{12}$ & 810.3693 & $2.50 \mathrm{E}+07$ & $4 \mathrm{~s}^{2}[3 / 2]_{1}{ }^{\circ}$ & 11.62 & $4 \mathrm{p}^{2}[3 / 2]_{1}$ & 13.15 \\
\hline$\lambda_{13}$ & 811.5311 & $3.31 \mathrm{E}+07$ & $4 \mathrm{~s}^{2}[3 / 2]_{2}{ }^{\circ}$ & 11.55 & $4 \mathrm{p}^{2}[5 / 2]_{3}$ & 13.08 \\
\hline$\lambda_{14}$ & 826.4522 & $1.53 \mathrm{E}+07$ & $4 \mathrm{~s}^{2}[1 / 2]_{1}{ }^{\circ}$ & 11.83 & $4 \mathrm{p}^{2}[1 / 2]_{1}$ & 13.33 \\
\hline$\lambda_{15}$ & 840.821 & $2.23 \mathrm{E}+07$ & $4 \mathrm{~s}^{2}[1 / 2]_{1}{ }^{\circ}$ & 11.83 & $4 \mathrm{p}^{2}[3 / 2]_{2}$ & 13.30 \\
\hline$\lambda_{16}$ & 842.4648 & $2.15 \mathrm{E}+07$ & $4 \mathrm{~s}^{2}[3 / 2]_{1}{ }^{\circ}$ & 11.62 & $4 \mathrm{p}^{2}[5 / 2]_{2}$ & 13.09 \\
\hline$\lambda_{17}$ & 852.1442 & $1.39 \mathrm{E}+07$ & $4 \mathrm{~s}^{2}[1 / 2]_{1}{ }^{\circ}$ & 11.83 & $4 \mathrm{p}^{2}[3 / 2]_{1}$ & 13.28 \\
\hline & & & & & \\
\hline
\end{tabular}

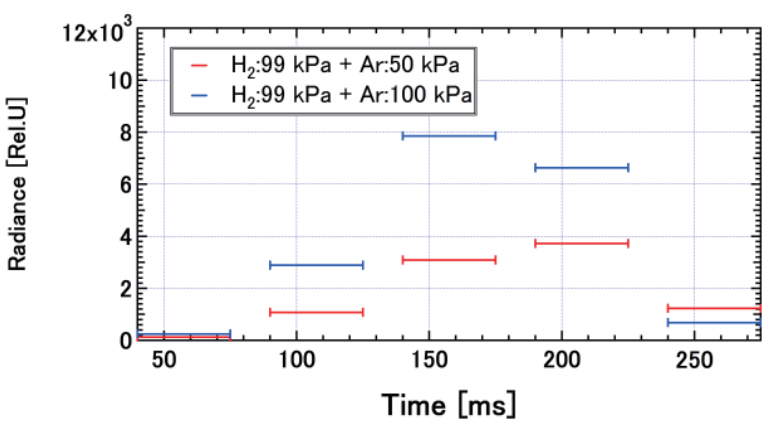

Fig. 7 Time behavior of the total radiance of neutral Ar emission.

Table 4 Radiation loss power and plasma parameters.

\begin{tabular}{|c|c|c|c|c|}
\hline $\begin{array}{c}\mathrm{H}_{2} \mathrm{Gas} \\
{\left[10^{4} \mathrm{~Pa}\right]}\end{array}$ & $\begin{array}{c}\text { Ar Gas } \\
{\left[10^{4} \mathrm{~Pa}\right]}\end{array}$ & $\begin{array}{r}\text { Ar I Radiance } \\
{[\text { Rel.U] }}\end{array}$ & $\begin{array}{c}\mathrm{Te} \\
{[\mathrm{eV}]}\end{array}$ & $\begin{array}{c}\text { ne } \\
{\left[10^{16} \mathrm{~m}^{-3}\right]}\end{array}$ \\
\hline \hline 0 & 0 & - & $40.8-46.8$ & $2.8-3.4$ \\
\hline $9.9 \pm 0.5$ & 0 & - & $7.5-9.9$ & $11.6-15.4$ \\
\hline $9.9 \pm 0.5$ & $5 \pm 0.3$ & 3100 & $4.0-7.0$ & $12.5-22.1$ \\
\hline $9.9 \pm 0.5$ & $10 \pm 0.5$ & 7900 & $3.0-3.6$ & $25.8-27.6$ \\
\hline
\end{tabular}

due to $\mathrm{H}_{2}$ and Ar gas injection. The correlation between the power of the radiation loss and the electron temperature was recognized from Table 4. It is suggested that the electron temperature is reduced by the above emission phenomena.

\section{Summary}

The spectral measurement system consisting of two spectrometers was developed in order to measure the detailed radiation behavior in D-module. The spatial distribution of the radiance of $\mathrm{H} \alpha$ on the $\mathrm{Z}$-axis in each angle of V-shaped target (30, 45, 60 degree) was investigated. In each angle, the radiance tended to decrease as leaving from plasma entrance. The decrease of the electron density due to the expansion of the magnetic flux tube in end-cell seems to be one of the causes that the radiance decreased. At every position, the radiance of $\mathrm{H} \alpha$ increased as the angle of V-shaped target became small. In the case the distance with the target plate becomes near, the effect of recycling seems to have an influence.

The experiment with $\mathrm{H}_{2}$ and $\mathrm{Ar}$ gas injection (plenum pressure: 5 and $10 \times 10^{4} \mathrm{~Pa}$ ) was performed. Primary line spectra of Ar I (17lines) were identified successfully. The radiation loss from Ar neutrals was also evaluated from intensity of spectra. A correlation between the power of radiation loss and the electron temperature in D-module are recognized.

From the above results, it is found that the spectral distribution in $\mathrm{H} \alpha$ intensity along the axial direction is affected by the angle of the target plate. This behavior indicates that the hydrogen recycling near the V-shaped target seem to play a role in the hydrogen radiance. A reduction of power of radiation loss evaluated in the case of the Ar injection also seems to indicate the effect of radiation cooling.

In the future, it is necessary that the ratio of the radiation loss power to the total power of plasma in D-module will be evaluated and that the power of radiation cooling in the other gas will be investigated.

\section{Acknowledgement}

This study was supported by the bi-directional collaboration research program from the University of Tsukuba, National Institute for Fusion Science (NIFS12KUGM066, NIFS11KUGM050). The authors thank the members of the GAMMA 10 groups for their collaboration in the experiments and their helpful discussions.

[1] Y. Nakashima et al., Fusion Eng. Des. 85, Issue 6, 956 (2010).

[2] T. Imai et al., J. Plasma Fusion Res. 87, 752 (2011) in Japanese.

[3] Y. Nakashima et al., Trans. Fusion Sci. Technol. 59, No.1T, $61(2011)$

[4] H. Takeda et al., Plasma Fusion Res. 7, 2405151 (2012).

[5] Y. Nakashima et al., J. Nucl. Mater. 438, 738 (2013).

[6] http://physics.nist.gov/PhysRefData/ASD/lines_form.html 